\title{
Poética y construcción textual en el Quijote
}

\author{
Luis MARTÍNEZ-FALERO \\ Universidad Complutense de Madrid \\ lmartinezfalero@filol.ucm.es
}

\begin{abstract}
RESUMEN
En este artículo proponemos un estudio del Quijote desde la perspectiva de las poéticas y retóricas del siglo XVI, que determinaron la concepción de la literatura en Cervantes. Asimismo, recogemos la literatura doctrinal, donde la novela de caballerías se convierte en objeto de censura. Con todo ello, pretendemos mostrar los orígenes teóricos y doctrinales que pudieron influir en Cervantes a la hora de escribir su obra.
\end{abstract}

Palabras clave: Cervantes, Poética renacentista, Retórica renacentista, Literatura doctrinal.

\begin{abstract}
In this article, a study of Don Quixote is proposed in perspective of poetics and rhetoric at 16th. Century, which brought the literary conception in Cervantes. Doctrinal literature is also collected, where the novel of knight-erranty is target of censure. With this materials, it is sought to display the theoretical and doctrinal origins which could be influence on Cervantes where he wrote his work.
\end{abstract}

Keywords: Cervantes, Renaissance poetics, Renaissance rhetoric, Doctrinal literature.

Intentar plantear nuevas perspectivas críticas a una obra tan estudiada como el Quijote supone una tarea imposible. Imposible, porque la bibliografía es tan amplia (potencialmente infinita, podríamos decir con un mínimo margen de error) que los posibles resquicios críticos, aquellos aspectos apenas estudiados o aún vírgenes, son, en todo caso, materia de microscopio electrónico más que de instrumental filológico.

Aún así, desde una perspectiva histórica, quisiera plantear en este artículo una aproximación desde la retórica y la poética (entendida ésta como segunda retórica) del Renacimiento, que es como decir desde la relectura de estas artes clásicas. Soy consciente de la imposibilidad de reconstruir de manera exacta, ni siquiera aproximada, el contexto de creación y recepción reales de una obra aparecida en los albores del siglo XVII, en cada uno de los aspectos que conforman cualquier texto literario como un producto creativo, y en el que confluyen aspectos literarios y 
extraliterarios, a veces de tan honda trascendencia como los valores ideológicos, los aspectos psicológicos en la compositio de la obra y la influencia del contexto social en la producción del texto. No obstante, siempre es posible una lectura individual que nos permita reestructurar los materiales de acuerdo con nuestra propia visión del texto, de igual manera que cada autor, guiado por la búsqueda de la originalidad, por dar un paso más allá de sus predecesores en la tarea literaria (quienes lo han formado como lector y -por tanto- como escritor) reestructura y rearticula las reglas compositivas, los tópicos y el resto de materiales necesarios para la creación poética (en puro sentido etimológico), a los que aporta un estilo individual para ofrecer un producto nuevo o, al menos, novedoso.

Hans Blumenberg, en La legibilidad del mundo ${ }^{1}$ ya nos advierte de que esa actividad creadora, sometida a reglas compositivas, tiene su fiel correlato en la actividad lectora, caracterizada por la necesaria reestructuración del material de lectura, pues parte de la psicología cognitiva de Jerry Fodor, basada en la modularidad de la mente. En nuestro cerebro se articulan percepciones, experiencias físicas y sentimentales y todo aquello que nos configura como el ser que somos, como el ser que escribe o que lee, capaz de transformar el mundo -nuestro mundoconcediendo un nuevo orden a los elementos que lo componen, reestructurando la realidad, concebida como un gran texto que hemos de leer de manera continua y atenta.

Si nos centramos en los aspectos meramente literarios de nuestra experiencia del mundo, nos construimos una cosmografía textual ${ }^{2}$ basada en nuestra memoria textual, de tal manera que esa cosmografía representa nuestro patrimonio, no por inmaterial menos cierto, donde inscribimos nuestra consciencia como individuos, nuestra historia como lectores y, en buena medida, nuestra actividad como creadores, desde el momento que articulamos ese mundo a través de una función textual que nos lleva a (re)crear mundos nuevos, a relacionar nuestras lecturas como constelaciones en las que acciones, personajes, espacios y tiempos cobran forma, se relacionan y rehacen en una actividad constante y siempre inacabada, siempre coherente (con la coherencia de ese mundo propio) y abierta a nuevas formas de expresión y sentido. Todo autor es el creador de un mundo. Ciertamente, pero también todo lector lo es. Por ello mi intención aquí es recomponer, al hilo de la preceptiva poética y retórica del Siglo de Oro y de algunos aspectos ideológicos subyacentes en ella, los materiales literarios contenidos en el Quijote, a los que Cervantes dio forma con una intención y con una disposición determinadas, y que trataré de analizar de manera lo más sucinta posible.

Comenzaremos, en nuestro recorrido, por los a priori literarios de los que parte el autor. En este punto es fundamental la actividad inventiva como búsqueda de elementos en torno a un núcleo de contenido, actividad psicológica guiada por el ingenio, en tanto que estructura profunda o nivel intensional, donde esa constelación de lecturas previas se reestructura para deducir un argumento nuevo sometido a unos rasgos genéricos. Actividad conceptual, por tanto, pues nos movemos aún en el

${ }^{1}$ H. Blumenberg (2000), pp. 22-23.

${ }^{2}$ Partimos en estos presupuestos de la teoría de Daniel Dubuisson (1996). 
margen de la abstracción, de las ideas sobre el texto que se van a materializar en él de acuerdo con una disposición, nivel extensional donde se manifiesta el bloque de contenido que se desea transmitir al lector, mediante una estructura pragmáticoactuativa que englobaría ambos niveles ${ }^{3}$. Así pues, partiendo del a priori genérico, consideraremos en primer lugar el concepto de novela y el lugar de la novela de caballerías y de otros subgéneros narrativos en esta categorización, para pasar después a los aspectos ideológicos sobre ambos temas en el Humanismo español, pues en este recorrido teórico, por la preceptiva literaria de la época, comprobaremos que ambos aspectos van íntimamente unidos.

Llevando a cabo el necesario escrutinio de los tratados de retórica y de poética, comprobamos la escasa atención que la ficción narrativa atrajo en los tratadistas del Renacimiento. La poesía y los géneros teatrales (sobre todo la tragedia) ocuparon una infinidad de páginas, frente a la ficción narrativa, cuya doctrina aparece dispersa y a veces confundida con la narratio retórica más pura, entendida como parte nuclear del discurso en los tres genera dicendi establecidos por Aristóteles. Generalmente, cuando se habla de narración ficticia, se unen y mezclan sus géneros y subgéneros, hasta el punto que en muchos tratados por texto épico en prosa se entienden textos tan dispares como la Historia etiópica de Heliodoro, el Amadís, el Asno de Oro de Apuleyo o el Lazarillo de Tormes, al que, sin embargo, Antonio Llull considera un diálogo de tipo moral, junto con el ya mencionado Apuleyo y los diálogos de Luciano $^{4}$, pues se trata de la "Segunda Parte" del Lazarillo (1555), donde la metamorfosis del protagonista posee una intención moralizante, como sucede con los antecedentes clásicos mencionados. Estas obras donde la metamorfosis del protagonista puede servir de vehículo para mostrarnos, de manera más o menos jocosa, una enseñanza moral (o leída de manera moral por los autores cristianos) están emparentadas con los adynata (o impossibilia) clásicos, ya utilizados por los Padres de la Iglesia para endulzar los rígidos principios doctrinales ${ }^{5}$. Volviendo al concepto de género narrativo, hemos de considerar la inserción del género histórico al mismo nivel que la historia ficticia que pone en liza a unos personajes que solo existieron en la imaginación de un autor y perviven en la de los lectores, dando así cuenta de un concepto de verosimilitud histórica rayana en la verdad lógica más pura. En esta línea de pensamiento, la novela de caballerías carecía de verosimilitud y lógica. Junto a esta crítica, se aducía la falta de rigor estilístico y la escasez de valores morales. Todo ello lo reúne Cervantes en el capítulo XLVII de la primera parte, cuando don Quijote afirma:

Verdaderamente, señor cura, yo hallo por mi cuenta que son perjudiciales en la república éstos que llaman libros de caballerías, y aunque he leído, llevado de un ocioso y falso gusto, casi el principio de todos lo más que hay impresos, jamás me he

\footnotetext{
${ }^{3}$ Cfr. A. García Berrio y T. Albaladejo Mayordomo (1983).

${ }_{5}^{4}$ A. Llull (1558), fol. 502.

${ }^{5}$ En este sentido, Curtius (1989), pp. 143-149. Para la tradición poética española del Siglo de Oro, Mayoral (2002).
} 
podido acomodar a leer ninguno del principio al cabo [...] Y según a según a mí me parece, este género de escritura y composición cae debajo de aquel de las fábulas que llaman milesias, que son cuentos disparatados que atienden solamente a deleitar, y no a enseñar, al contrario de lo que hacen las fábulas apólogas, que deleitan y enseñan juntamente. [...] Pues ¿qué hermosura puede haber, o qué proporción de partes con el todo y del todo con las partes en un libro o fábula donde un mozo de diez y seis años da una cuchillada a un gigante como una torre y le divide en dos mitades, como si fuera de alfeñique $[. .$.$] ? ¿Qué ingenio, si no el del todo bárbaro e inculto, podrá contentarse$ leyendo que una gran torre llena de caballeros va por la mar adelante, como nave con próspero viento, y hoy anochece en Lombardía y mañana amanezca en tierras del Preste Juan de las Indias, o en otras que ni las describió Tolomeo ni las vio Marco Polo? [...] Hanse de casar las fábulas mentirosas con el entendimiento de los que las leyeren, escribiéndose de suerte que facilitando los imposibles, allanando las grandezas, suspendiendo los ánimos, admiren, suspendan, alborocen y entretengan, de modo que anden a un mismo paso la admiración y la alegría juntas; y todas estas cosas no podrá hacer el que huyere de la verisimilitud y de la imitación, en quien consiste la perfección de lo que se escribe. No he visto ningún libro de caballerías que haga un cuerpo de fábula entero con todos sus miembros [...] Fuera desto, son en el estilo duros; en las hazañas, increíbles; en los amores, lascivos; en las cortesías, malmirados; largos en las batallas, necios en las razones, disparatados en los viajes, y, finalmente, ajenos de todo discreto artificio y por esto dignos de ser desterrados de la república cristiana, como a gente inútil ${ }^{6}$.

En este asunto Cervantes se decanta claramente por el neoaristotelismo que inspira las poéticas del Siglo de Oro. Su concepto de "novela", no solo delineado en varios pasajes del Quijote (como "El curioso impertinente", donde se incide en la falta de verosimilitud del relato), sino también en alguna de sus Novelas ejemplares (El coloquio de los perros), está fundamentado por el concepto de imitación tal como fue formulado por Aristóteles, es decir, el texto de ficción debe mostrar acciones posibles tal como podrían suceder, por lo que su fin es la verosimilitud. Esta concepción neoaristotélica, en la preceptiva necesaria para afrontar una compositio de acuerdo con la finalidad discursiva propuesta (movere, docere, delectare), nos traslada a los conceptos asumidos por los tratadistas del Renacimiento, partiendo de los italianos (Tasso, Piccolomini, Pigna, Minturno o Escalígero ${ }^{7}$ ) y desembocando en los españoles, hasta alcanzar la época de plena creación de Cervantes (Llull, Carballo o López Pinciano). Es precisamente a López Pinciano, y su Philosophia antigua poética (1596), a quien la crítica ha atribuido un mayor peso sobre la poética cervantina, o, en todo caso, un mayor grado de coincidencia. Ello puede probarse comparando el pasaje anterior, el discurso puesto en boca de don Quijote, con las siguientes afirmaciones del Pinciano:

Y comenzando en el nombre de Dios, digo que la fábula es imitación de la obra. Imitación ha de ser porque las ficciones que no tienen imitación y verosimilitud, no son

${ }^{6}$ M. de Cervantes (1998), pp. 547-549.

${ }^{7}$ E. C. Riley (2004), pp. 85-86. 
fábulas sino disparates, como algunas de las que antiguamente llamaron milesias, agora libros de caballerías, los cuales tienen acaecimiento fuera de toda buena imitación y semejanza a verdad. ${ }^{8}$

Esta visión negativa de los libros de caballerías la podemos matizar en Antonio Llull, en el libro tercero de su tratado De oratione, cuando, al establecer las propiedades de la narración, asegura:

El Amadís español enseña los preceptos de la nobleza y del decoro de los príncipes, sin duda impregnado de un gran deleite, pero solo enseña a los hijos de los príncipes a leer y a hablar, pero no a hablar con elocuencia o a narrar, como no enseñan otros muchos del mismo género, a los que esta obra ha dejado a mucha distancia detrás de sí en cuanto a la disposición y orden de los hechos. ${ }^{9}$

Para Llull, como para los demás tratadistas, no solo importa el deleite como finalidad discursiva (y no olvidemos que en esa concepción de deleite prima lo intelectual, basado en la perfección compositiva de la obra ${ }^{10}$ ), sino fundamentalmente los valores morales que se deben transmitir como enseñanza, por cuanto, para el tratadista mallorquín y el resto de humanistas, la obra literaria (retórica en sus componentes) debe reflejar la perfección de la obra divina. Como vemos, el mundo del texto vuelve a incidir sobre el mundo real; la creación literaria, sobre la creación del mundo; el libro, sobre la lectura de ese mundo creado. Porque las objeciones a las novelas de caballerías no solo vienen de los tratadistas de retórica o poética, sino del componente moral que impregna los trabajos de filósofos, teólogos o gramáticos. La cuestión no se centra únicamente en las lagunas estéticas, estilísticas o formales, que deshacen la verosimilitud del relato (del roman, si se prefiere una adscripción genérica más exacta con la doctrina literaria de la época), sino en el éxito entre el público del siglo XVI, junto a los demás subgéneros narrativos: la novela picaresca, la sentimental, la morisca, la pastoril y la bizantina o de aventuras, quizá la única que se salva del severo escrutinio de los moralistas, pues siempre las pruebas vencidas con éxito concluyen con la felicidad ante el premio prometido. De ahí seguramente la preferencia de Cervantes por este tipo de ficción. El éxito de los libros de caballerías entre el público es un hecho determinante, pues aparta a la población de la recta doctrina, los lleva a mundos de ficción donde el héroe no se somete a ninguna norma moral: recordemos que el caballero Amadís de Gaula mantuvo su actividad amorosa hasta más allá de los ochenta años, con el vigor de un muchacho y sin demasiado remordimiento ante lances amorosos en pecado. Riley considera que el público mayoritario de este tipo de novelas era la aristocracia (formada por nobles e hidalgos) que veían en los libros de caballerías, con cierta nostalgia, las pasadas glorias

\footnotetext{
${ }^{8}$ A. López Pinciano (1998), p. 172.

${ }^{9}$ A. Llull (1558), fol. 215.

${ }^{10}$ A. Llull (1558), fol. 5.
} 
medievales ${ }^{11}$; además, es necesario tener en cuenta a la clase media urbana y a las mujeres, practicándose o bien una lectura en silencio o bien la lectura en voz alta, lo que permitía, asimismo, la aparición de un auditorio ${ }^{12}$.

Para los moralistas, el público más influenciable por estas lecturas eran las mujeres, quienes se apartaban de sus tareas domésticas y de su devoción, atraídas por estos relatos. Por otra parte, al tratarse de prosa, la interpretación y asimilación de los contenidos era más sencilla, por lo que tampoco se requería de una formación especial, que, junto a la lectura en silencio, es decir, con toda la atención centrada en el texto, llevaba a dejar correr libre la imaginación y a permitir una mayor identificación con el texto ${ }^{13}$. De ahí el rechazo visceral del humanismo latino hacia la literatura en las lenguas vernáculas, que permitía el fácil acceso a los textos sin ser necesaria una educación previa que, además, formara el juicio del lector y no lo desviara de la rectitud doctrinal. Curiosamente, en este punto coinciden tanto protestantes como erasmistas y católicos seguidores de la más firme ortodoxia. Los primeros, porque Lutero, en su De servo arbitrio (1525), había rechazado cualquier asimilación de las letras profanas en la formación o lectura recreativa de sus seguidores, a pesar de los muchos matices introducidos por Philip Melanchton y Johannes Sturm en las doctrinas pedagógicas de la Reforma. Los erasmistas y los católicos ortodoxos, porque veían un alejamiento de los valores espirituales y religiosos que ponían en peligro la rígida moral que debían guardar los fieles. Veamos esta doble visión de la mujer lectora (la procedente del erasmismo y la tridentina) antes de entrar en las causas del Quijote desde este plano moral.

Marcel Bataillon, siguiendo a Menéndez Pelayo, nos indica las posibles raíces ideológicas de Cervantes ${ }^{14}$. En primer lugar, las enseñanzas de su maestro López de Hoyos sitúan al escritor alcalaíno en el contexto de la doctrina erasmista transmitida en la clandestinidad y que Cervantes muestra en el repertorio de apotegmas de que se sirve Tomás Rodaja, protagonista de El licenciado Vidriera $^{15}$ y cuya fuente se halla en los Apotegmata ex optimis excriptoribus erasmianos (1531), que conocieron diversas ediciones a lo largo del siglo XVI y que, una vez expurgados de la posible materia herética, continuaron su difusión por Europa, incluida España ${ }^{16}$. También encuentra el estudioso francés relación entre las ideas religiosas contenidas en el Quijote con las críticas a la jerarquía eclesial y con el iluminismo de Erasmo. Sin embargo, el punto fundamental de apoyo para relacionar a Cervantes con la escuela erasmista es su coincidencia en la crítica sobre las novelas de caballerías, común a

${ }^{11}$ Sobre los motivos de la recepción de la novela de caballerías por la aristocracia, M. S. Carrasco Urgoiti (2001), p. 21.

${ }^{12}$ E. C. Riley (2004), p. 17.

${ }^{13}$ B. W. Ife (1992), p. 14.

${ }^{14}$ M. Bataillon (1998), pp. 777 y ss. Las consideraciones de M. Menéndez Pelayo (1907), pp. 1-64.

${ }^{15}$ M. Bataillon (1998), p. 779.

${ }^{16}$ M. Bataillon (1998), p. 503n. 
Vives o Juan de Valdés ${ }^{17}$. Precisamente es Luis Vives quien, en su De institutione Christianae Feminae (1523; primera edición en castellano, 1528) ofrece una lista de lecturas que deben ser prohibidas a las mujeres, pues las convierten en "maliciosas y perversas". Entre ellas, las obras españolas Amadís, Esplandián, Florisel, Tirant, Tristán de Leonís, La Celestina, y la Cárcel de amor; las francesas Lanzarote del Lago, Paris y Viana, Ponto y Sidonia, Pedro Provenzal, Magalona y Melusina; de las publicadas en Bélgica, Flores y Blancaflor, Leonela y Canamor, Curias y Floreta o Píramo y Tisbe; y ello sin olvidar el Decamerón de Boccaccio, el Liber facetiarum de Poggio Bracciolini y a Euríalo o a los poetas grecolatinos de tema amoroso al completo $^{18}$. Novelas de caballerías, sentimentales, pastoriles, satíricas... todas deben ser borradas de las lecturas femeninas para ser sustituidas por textos más instructivos en la doctrina cristiana, a saber: los Evangelios, los Hechos de los Apóstoles, San Jerónimo, San Agustín, San Gregorio, Boecio, Tertuliano, Platón, Cicerón, Séneca... y de los poetas, solo poetas latinos cristianos o asimilables al cristianismo ${ }^{19}$. En una censura semejante coincide Juan de Valdés en su Diálogo de la lengua, aunque con ciertos e importantes matices, al salvar el Amadís y algún otro libro de caballerías. Recomienda también la lectura de los Padres de la Iglesia, las Epístolas y los Evangelios, vidas de santos y autores clásicos como Tito Livio, César, Valerio Máximo, Quinto Curcio... Sobre las novelas de caballerías considera lo siguiente:

Por ventura yo no alabo ninguno déssos porque no los he leído; por eso no os devéis maravillar, y haréis mejor en dexarme dezir. Entre los que an escrito cosas de sus cabeças comúnmente se tiene por mejor estilo el del que scrivió los quatro libros de Amadís de Gaula; y pienso que tienen razón, bien que en muchas partes va demasiadamente afetado, y en otras muy descuidado; unas vezes alça el estilo al cielo, y otras lo abaxa al suelo; pero al fin, assí a los quatro libros de Amadís, como a los de Palmerín y Primale6n, que por cierto respeto an ganado crédito conmigo, terné y juzgaré siempre por mejores que essotros Esplandián, Florisando, Lisuarte, Cavallero de la Cruz, y que a los otros no menos mentirosos que éstos, Guarino mezquino, La linda Melosina, Reinaldos de Montalván, con la Trapisonda, y Oliveros que es intitulado de Castilla, los quales, demás de ser mentirosíssimos, son tan mal compuestos, assí por dezir las mentiras muy desvergonçadas, como por tener el estilo desbaratado, que no ay buen estómago que los pueda leer. ${ }^{20}$

Más que por influencia erasmista, y los ejemplos que acabamos de mencionar son elocuentes, aunque encajan con dificultad en el ideario cervantino plasmado en el Quijote, nos inclinamos a considerar el espíritu tridentino puesto en práctica por los moralistas y por tratadistas de retórica como Benito Arias Montano, quien asistió a Trento. En el libro tercero de sus Rhetoricorum libri quatuor (1569) nos indica (en los versos 399 a 411):

\footnotetext{
${ }^{17}$ M. Bataillon (1998), p. 780.

18 J. L. Vives (1538), fols. 24-27.

${ }^{19}$ J. L. Vives (1538), fols. 27-29.

${ }^{20}$ J. de Valdés (1982), pp. 247-248.
} 
En efecto, a los escritos que con mucha frecuencia se editan por nuestros reinos en forma de libros y que hablan de antiguos y errantes caballeros: los caudillos Orlando, Esplandián el Griego y Palmerín, etc., los llamamos monstruos, parto de una estúpida fantasía, hez de los libros, basura recogida para ruina de nuestro tiempo y sin mejor objetivo que corromper las costumbres de los hombres. Aquí no se conserva el orden temporal ni la lógica en los lugares y, si algo de ello por ventura se encontrara, ni se podría creer ni podría deleitar cuanto se leyera, a no ser que te deleite la propia visión del vicio bochornoso y el sucio placer: lo que allí se lee son crueles costumbres y heridas infligidas a enemigos que no existen, pero inventadas de una forma estúpida. ${ }^{21}$

"Heridas infligidas a enemigos que no existen". La imaginación crea monstruos al volar en libertad. En el texto de Arias Montano podemos resumir los cuatro argumentos principales contra la ficción, que enumera Ife referidos a los géneros narrativos (épicos en prosa romance) del Renacimiento español: la ficción da mal ejemplo, favorece el disfrute de experiencias ajenas, falsifica la realidad y socava la autoridad de la verdad ${ }^{22}$. Es esa misma imaginación monstruosa la que transgrede los límites de la moralidad, corrompe las costumbres del género humano, máxime cuando hay mujeres que no solo leen novelas de caballerías, sino que las escriben, como Beatriz Bernal y su Don Cristalián de España (Valladolid, 1545), en pleno apogeo de la publicación de este tipo de novelas, algunas con títulos tan sonoros como el Florambel de Lucena, de Francisco Enciso de Zárate (1532); el Felixmarte de Hircania, de Melchor Ortega (1556); o el Policisne de Boecia, de Juan de Silva y de Toledo (1602). Ciertamente, con tales títulos la parodia estaba casi servida.

Esta moralidad en peligro, si no abiertamente abocada al abismo, tiene muchos y esforzados defensores, verdaderos paladines de la fe, que se enfrentan con todas sus armas a estos libros, dulces en su apariencia, pero ponzoñosos en su contenido. Como señala el jesuita Gaspar de Astete (en su Tratado del gobierno de la familia y estado de las viudas y doncellas, 1597): "Las fábulas y patrañas que los libros semejantes cuentan, son dulces quando se leen, mas después amargan y corrompen las almas"23, coincidiendo con fray Antonio de Guevara (en su Aviso de privados y doctrina de cortesanos, $1539^{24}$ ). Junto a él, entre otros muchos, fray Juan de la Cerda, Diego de Cabranes, fray Ortiz Lucio, el padre Francisco de Rivera y, sobre todo, fray Pedro Malón de Chaide (La conversión de la Magdalena, 1588), quien arremete contra toda la literatura profana, en verso y en prosa:

Como si no bastaran los ruines siniestros con que nacemos y los que mamamos en la leche, y los que se pegan en la niñez con el regalo que en aquella edad se nos hace; y como si nuestra gastada naturaleza, que de suyo corre desapoderada al mal, tuviera

${ }^{21}$ B. Arias Montano (1984), pp. 126 y 128.

${ }^{22}$ B. W. Ife (1992), pp. 24-35.

${ }^{23}$ G. de Astete (1603), p. 176.

24 "Porque su doctrina incita la sensualidad a pecar, y relaja el espíritu a buen vivir", en A. de Guevara (1904), pp. 45-46. 
necesidad de espuela y de incentivos para despertar el gusto del pecado, así la ceban con libros lascivos y profanos, a donde y en cuyas rocas se rompen los frágiles navíos de los mal avisados mozos, y las buenas costumbres (si algunas aprendieron de sus maestros) padecen naufragios y van a fondo y se pierden y malogran. Porque ¿qué otra cosa son los libros de amores y las Dianas y Boscanes y Garcilasos puestos en manos de pocos años, sino cuchillo en poder de hombre furioso? ¿Qué ha de hacer la doncellita que apenas sabe andar, y ya trae una Diana en la faldriquera? Otros leen aquellos prodigios y fabulosos sueños y quimeras, sin pies ni cabeza, de que están llenos los Libros de Caballerías, que así los llaman a los que, si la honestidad del término lo sufriera, con trastocar pocas letras se llamaran mejor de bellaquerías que de caballerías. $^{25}$

El origen del Quijote se encuentra en la censura de los libros de caballerías, al menos en la primera parte, pues en la segunda, movido por el éxito, mantiene una mayor linealidad narrativa y cuidado en la composición, mientras que la ironía sobre su propia creación y sobre el Quijote de Avellaneda hace cambiar el planteamiento de la narración. Cervantes califica su propia obra con los términos que corresponden, en esta tradición humanista y contrarreformista que acabamos de considerar, “...con una leyenda seca como el esparto, ajena de invención, menguada de estilo, pobre de concetos y falta de toda erudición y doctrina..." ${ }^{26}$. La primera parte posee, por tanto, un claro carácter ejemplar, siguiendo la definición del exemplum retórico, en cuanto a que se establece una "comparación con el pensamiento propiamente dicho" 27 , añadiendo un significado extra al sentido literal del texto. Esta ejemplaridad, cuyo fin es la moralización a través de un argumentum risibile, que no solo enseñe sino que deleite, se ve sometida a una amplificatio que convierte la brevedad del exemplum en un desarrollo narrativo complejo. Con ello se pretende mover los ánimos y dejar mayor huella del contenido textual. En este sentido, el concepto clásico de parodia, mantenido por Escalígero en sus Poetices libri septem (1557), nos proporciona otra de las claves, al considerar como parodia la inclusión de elementos ajenos a un género (como, por ejemplo, pertenecientes a la tragedia) en un texto de otro género (como la comedia). Esta mezcla de actantes genéricos tiene por finalidad la sátira y la trivialización del género cuyos elementos se han descontextualizado ${ }^{28}$. En una línea similar parece apuntar Antonio Llull cuando denomina parodia a la enunciación marcada por la simulación, es decir, cuando queremos añadir valores a un sentido inicial de nuestras palabras, pues -rompiendo la tripartición de Quintiliano (Institutio oratoria 6.3 .85 y 8.6.54) entre simulación, ironía y fingimiento ${ }^{29}$ - alcanza la necesidad de la ironía como único tropo que indica un significado opuesto al que parecen indicar los términos de un enunciado como elemento fundamental para la construcción de la parodia. Para el tratadista balear, la parodia debe estar revestida

\footnotetext{
${ }^{25}$ P. Malón de Cahide (1959), pp. 23-27.

${ }^{26}$ M. de Cervantes (1998), p. 11.

${ }^{27}$ H. Lausberg (1993), p. 204.

${ }^{28}$ J. C. Escalígero (1561), fol. 46.

${ }^{29}$ A. Llull (1558), fols. 306 y 471.
} 
por un estilo revelador del carácter, siendo su cualidad principal la habilidad ${ }^{30}$, de acuerdo con la clasificación de estilos fijada por Hermógenes en su tratado Sobre los tipos de estilo. La finalidad moral, transmitida a través de una parodia textual, se alcanza mediante la inversión de elementos: frente a los lugares exóticos o eufónicos de donde proceden los héroes caballerescos (Gaula - ¿Gales?-, Trebisonda, Hircania, Boecia...), se contrapone el árido páramo manchego de don Quijote; frente a los caballos míticos (Bucéfalo, Babieca, Marmorio, Veillantif...) se sitúa un rocín flaco, Rocinante; frente a la lozanía y fuerza del héroe, la figura del hidalgo entrado en años... Para reforzar los paralelismos y no perder el referente, Cervantes cita en su narración unos sesenta episodios del Amadís.

Es precisamente en esta orientación moral, con el docere como finalidad discursiva, donde cobra sentido la variatio manifestada en las narraciones intercaladas en el relato principal de los desdichados lances de don Quijote como caballero andante. Como señala Lausberg: "El docere se halla expuesto al peligro del toedium y necesita por ello ir acompañado del delectare [...] La simpatía del público hacia el discurso (y, con ello, indirectamente hacia el asunto y el orador) se logra con la variatio, 31 .

Con el fin de romper esa sucesión de hechos desastrosos acaecidos al antihéroe, Cervantes intercala en su obra una serie de narraciones, pertenecientes a varios de los géneros en boga en su época, así como composiciones poéticas de diverso tipo. La intercalación de narraciones no era un recurso nuevo, pues ya en La gran conquista de ultramar (original latino del siglo XII, versión francesa del siglo XIII y versión castellana del siglo XIV) se intercala la historia del Caballero del Cisne en el extenso relato de las Cruzadas. Más próximo a Cervantes, Mateo Alemán introdujo una novela morisca (la de Ozmín y Daraja) en el último capítulo del libro primero del Guzmán de Alfarache (1599). Con esa inserción de otros tipos de narración, Cervantes busca el delectare a partir de la variatio, mostrando, además, su conocimiento de la técnica narrativa necesaria para afrontar la creación de textos sometidos a una convencionalidad propia. Así, en la Primera Parte del Quijote, hallamos un relato bucólico-pastoril y sentimental con Marcela y Grisóstomo como protagonistas (capítulos XII al XIV); las novelitas sentimentales centradas en las figuras de Cardenio y Luscinda, y Dorotea y don Fernando (capítulos XXIII al XLVII), durante la estancia en Sierra Morena; otro relato sentimental, el de Clara y don Luis, intercalado con la novella italiana del "Curioso impertinente" (capítulos XXXIII al XXXV); la novela morisca narrada por el cautivo (capítulos XXXIX a XLI); y el relato bucólico pastoril de la historia de Leandra (capítulo LI); junto a los caracteres de la picaresca del personaje Ginés de Pasamonte. Ahora bien, algunos de estos relatos no solo se intercalan en el corpus principal de la narración, a manera de digresiones, sino que se ven interrumpidos por esa línea principal. De este modo, la lectura de la novella del "Curioso impertinente" se ve interrumpida con los episodios de los cueros de vino; las novelas sentimentales de Cardenio y Luscinda y de Dorotea

\footnotetext{
${ }^{30}$ A. Llull (1558), fol. 471.

${ }^{31}$ H. Lausberg (1983-I), p. 229.
} 
y Fernando con el "Discurso de las armas y las letras", todos ellos narrados con la venta como contexto. No sucede lo mismo en la Segunda Parte, la publicada en 1615, donde estas narraciones intercaladas mantienen su propia línea argumental sin interrupciones, formando parte del argumento principal del texto, es decir, perdiendo su carácter digresivo: así lo podemos comprobar en los relatos sentimentales de Basilio y Quiteria (capítulos XIX a XXII), la historia de doña Rodríguez y la de Claudia Jerónima (capítulo LX), junto a los relatos moriscos de Ricote y de Ana Félix (Ricotita) (capítulos LIV y LXIII a LXV, respectivamente). Cada uno de estos tipos de narración responde a los caracteres canónicos marcados por la convención literaria, atendiendo a sus antecedentes históricos. Algunos críticos, sin embargo, como Riley, consideran que, al menos en lo referente a la novela pastoril, existe un ánimo de parodia por parte de Cervantes ${ }^{32}$, quien había publicado en $1585 \mathrm{La}$ Galatea, novela pastoril que sigue fielmente el modelo de la Diana de Jorge de Montemayor (1559). Por otra parte, Stephen Gilman considera que este recurso, la intercalación de narraciones con variedad de géneros y recursos, supone una técnica narrativa que, partiendo precisamente de La Galatea, proporciona al relato una frescura renovada, sin necesidad de perder un hilo argumental principal y sostenido ${ }^{33}$. Esta unión de géneros crea la novela moderna, al mismo tiempo que muestra el entramado genérico renacentista, puesto a debate moral. Como señala el propio Gilman:

Ésa era la forma de llamar la atención acerca de una interpretación sin precedentes, y acerca de la interdependencia de la crítica y la creación en su arte de componer novelas [...] Esta novela [...] fue concebida como un tejido sistemático, calculado y cuidadoso, cuya urdimbre fue la invención creadora y cuya trama fue la meditación crítica. En ella, la ficción se crea [...] en el acto de destruir la ficción. ${ }^{34}$

Crear literatura es descrear el mundo. Por ello, Cervantes no duda en mostrar los hilos de su trama, la ficción de su ficción (Cervantes vs. Cide Amete Benengeli; don Quijote vs. Amadís, etc.), al afirmar la pluma de Cide Amete, como colofón a la "vida" de don Quijote:

Para mí sola nació don Quijote, y yo para él; él supo obrar y yo escribir, solos los dos somos para en uno, a despecho y pesar del escritor fingido y tordesillesco que se atrevió o se ha de atrever a escribir con pluma de avestruz grosera y mal deliñada las hazañas de mi valeroso caballero, porque no es carga de sus hombros, ni asunto de su resfriado ingenio. ${ }^{35}$

La ficción habla de sí misma, marca los límites de su mundo, pero, al tiempo, abre los de nuestro propio mundo como lectores del Quijote. Cervantes cierra su libro

${ }^{32}$ E. C. Riley (2004), p. 56.

${ }^{33}$ S. Gilman (1993), p. 62.

${ }^{34}$ S. Gilman (1993), p. 144.

${ }^{35}$ M. de Cervantes (1998), p. 1223. 
de libros y abre el libro de una concepción narrativa nueva. He aquí quizá el sentido final de la escritura.

\section{OBRAS CITADAS}

ARIas Montano, Benito: Los Rhetoricorum libri quatuor de Benito Arias Montano, ed. de $\mathrm{M}^{\mathrm{a}}$ Violeta Pérez Custodio, Badajoz, Diputación Provincial, 1984.

ASTETE, Gaspar (de): Tratado del gobierno de la familia y estado de las viudas y doncellas, Burgos, Juan Baptista Varesio, 1603.

BATAILLON, Marcel: Erasmo y España, Madrid, F.C.E., 1998.

BLumenBerg, Hans: La legibilidad del mundo, Barcelona, Paidós, 2000.

CARRASCo URGOITI, $M^{a}$ Soledad: "Los libros de caballerías. La novela morisca. Los libros de cuentos", en $\mathrm{M}^{\mathrm{a}} \mathrm{S}$. Carrasco, F. López Estrada y F. Carrasco, La novela española en el siglo XVI, Madrid, Iberoamericana / Vervuet, 2001, pp. 15-50.

Cervantes, Miguel (de): Don Quijote de la Mancha, ed. dirigida por Francisco Rico, Barcelona, Crítica/Instituto Cervantes, 1998.

CURTIUS, Ernst Robert: Literatura europea y Edad Media latina, Madrid, F.C.E., 1989, 2 vols.

DUBUISSON, Daniel: Anthropologie poétique. Esquisses pour une anthropologie du texte, Lovaina-la-Nueva, Peeters, 1996.

EsCALÍGERO, Julio César: Poetices libri septem, Lyon, Apud Antonium Vincentium, 1561.

GARCÍA BERrio, Antonio y ALBALADEJO MAYORDOMO, Tomás: "Estructura composicional. Macroestructuras", Estudios de Lingüistica Universidad de Alicante, 1 (1983), pp. 127-175.

GILMAN, Stephen: La novela según Cervantes, México D.F., F.C.E., 1993.

Guevara, Antonio (de): Aviso de privados y doctrina de cortesanos, en Despertador de cortesanos, ed. de A. Álvarez de la Villa, París, 1904.

IFE, Barry W.: Lectura y ficción en el Siglo de Oro. Las razones de la picaresca, Barcelona, Crítica, 1992.

LAUSBERG, Heinrich: Manual de retórica literaria, Madrid, Gredos, 1983, 3 vols.

- Elementos de retórica literaria, Madrid, Gredos, 1993.

Llull, Antonio: De oratione libri septem, Per Ioannem Oporinum, 1558.

LÓPEZ PINCIANO, Alonso: Philosophia antigua poética. Obras completas I, Madrid, Biblioteca Castro, 1998.

MALÓN DE CHAIDE, Pedro: La conversión de la Magdalena, Madrid, Espasa-Calpe, 1959.

MAYORAL, José Antonio: "Ficción de imposibles", en Estructuras retóricas en el discurso poético de los siglos XVI y XVII, Valencia, Tirant lo Blanch, 2002, pp. 43-73.

MenÉndez Pelayo, Marcelino: Cultura literaria de Cervantes y elaboración del "Quijote”, Madrid, 1907.

RILEY, Edward C.: Introducción al "Quijote”, Barcelona, Crítica, 2004. 
VALDÉS, Juan (de): Diálogo de la lengua, ed. de Cristina Barbolani, Madrid, Cátedra, 1982.

VIVES, Juan Luis: De institutione Christiance Femince, Basilea, Per Robertum Winter, 1538. 